\title{
PERANCANGAN SISTEM INFORMASI INVENTARIS LABORATORIUM KOMPUTER PADA SMK NEGERI 2 BANJARMASIN MENGGUNAKAN DELPHI 7.0
}

\author{
Fitrah Yuridka ${ }^{1}$, Rais Wathani ${ }^{2}$ \\ ${ }^{1}$ Teknologi Informasi, Universitas Islam Kalimantan Muhammad Arsyad Al Banjari Banjarmasin \\ Email : yvitrah@yahoo.co.id \\ ${ }^{2}$ Teknologi Informasi, Universitas Islam Kalimantan Muhammad Arsyad Al Banjari Banjarmasin \\ Email Raiswathani@gmail.com
}

\begin{abstract}
ABSTRAK
Pada SMK Negeri 2 Banjarmasin pendataan untuk Sistem informasi Inventaris barang computer masih bersifat manual sehingga dalam pengarsipan data ini masih tidak tersusun rapi, hal ini sangat memberikan dampak bagi pihak sekolah terutama apabila ada audit system serta pelaporan data-data mengenai inventaris laboratorium, Dimana pada SMK Negeri 2 terdiri dari laboratorium perakitan PC dan Laptop, Laboratorium Pemrograman dan Jaringan, Laboratorium RPL, Dan Laboratorium Multimedia. Mengingat Jumlah Laboratorium yang cukup banyak maka Perancangan system informasi serta pembuatan aplikasi Delphi 7.0 sangat diperlukan untuk membantu pengarsipan data pada inventaris laboratorium Komputer pada SMK Negeri 2 yang digunakan ketua laboratorium dalam pelaporan Inventaris di sekolah salah satu contoh laporan barang yang bersifat computer maupun non computer serta laporan jika terdapat mutasi barang dari satu laboratorium ke laboratorium lainnya dan laporan peminjaman barang laboratorium.
\end{abstract}

Kata Kunci :InventarisLaboratoriumKomputer, SMK Negeri 2 Banjarmasin, Delphi 7.0

Jurnal Ilmiah "Technologia” 


\section{PENDAHULUAN}

Ilmu pengetahuan dan teknologi berkembang semakin pesat mendorong manusia untuk meningkatkan,bahkan menciptakan sebuah teknologi baru yang dapat lebih bermanfaat dan mempermudah kehidupan manusia.Perkembangan teknologi informasi ditandai dengan perkembangan teknologi computer dan teknologi komunikasi, membuat setiap instansi atau lembagadituntut untuk memiliki infrastruktur teknologi informasi yang baik.Di era globalisasi sekarangini, seluruh system pelayanan diotomatisasi dengan peralatan yang bersifat efisien dalam hal waktu dan tenaga.Sistem inventory dapat diartikan sebagai suatu aplikasi yang meliputi input, proses dan output dimana data yang diolah merupakan data dari seluruh perlengkapan (data barang) yang dimiliki oleh labkom SMKN 2 Banjarmasin. Selama inisistem inventory yang dimilikioleh SMKN 2 Banjarmasin masih menggunakan cara manual, yaitu berupa arsiparsip inventaris tiap ruang (labkom).

Berdasarkanhaltersebut,

makadibuatsebuahsisteminformasi inventory labkom di SMKN 2 Banjarmasin.Sistem inventory inidapatmempermudah proses inventarisasisemuabarang yang ada di labkom SMKN 2 Banjarmasin.

\section{METODE PENELITIAN}

\subsection{MetodePengumpulan Data}

Data primer merupakan data yang langsung dapat dan disajikan sebagai sumber dari penelitian dan pengamatan secara langsung pada objek atau perusahaan tempat melakukan penelitian, dimana dilakukan dengan cara penelitian lapangan melalui observasi dan wawancara dengan pihak yang berkaitan langsung dengan penelitian yang dilakukan, sedangkan data sekunder adalah dengan cara studi literatur dan wawancara. analisa data dan hasil.

\subsection{Tahap-Tahap Pembuatan Sistem}

\section{Analisis Sistem}

Tahap yang dilakukan untuk pengembangan perangkat lunak ini adalah menggunakan metode waterfall, dimana tahapan-tahapannya adalah sebagai berikut :

a. Requirement Analysis / Analisa Kebutuhan :Menganalisa kebutuhan kebutuhan yang diperlukan untuk mengembangkan aplikasi. Fase ini dapat diperoleh melalui wawancara, diskusi, survey, riset maupun dari kritik dan saran sering disebut studi literatur.

b. System Design / DesainSistem :Tahap yang dilakukan sebelum kita menerapkan syntax atau kode-kode program.

c. Implementation / Implementasi : Tahap perancangan kode atau syntax

d. Integration \& Testing / Integrasi dan pengujian :melakukan koding ulang terhadap kesalahan sampai error dapat ditangani.

e. Operation \& Maintenance / Penggunaan dan Pemeliharaan :seiring berjalannya waktu pengguna aplikasi pasti menemukan bug / error kecil yang tidak ditemukan pada saat pengujian, dan pada fase ini lah melakukan perbaikan - perbaikan terhadap aplikasi. Pada tahap ini tidak selalu harus terjadi error untuk melakukan fase ini, menemukan sesuatu yang tidak sesuai atau bisa diubah menjadi lebih baik, maka tahap ini bisa dilakukan juga.

\section{Perancangan Sistem}

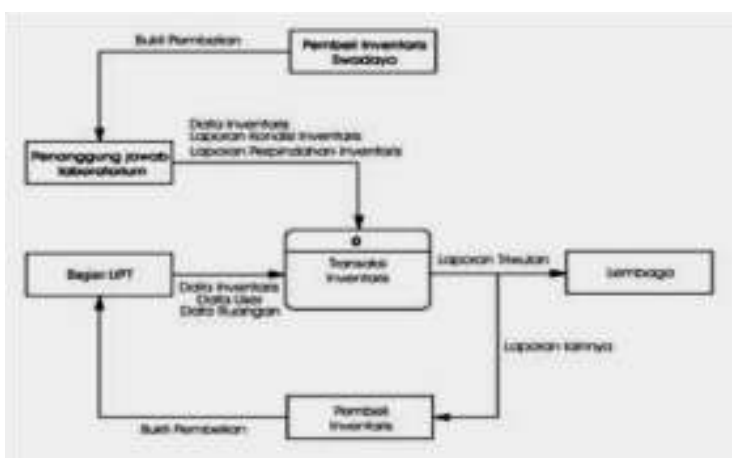

Gambar 1. Diagram Konteks 


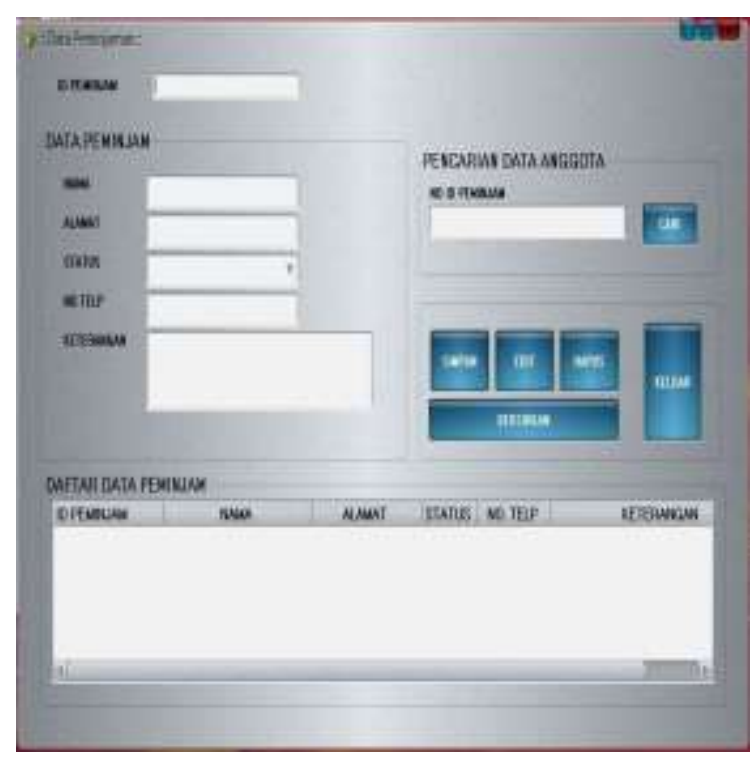

Gambar 2.TampilanPeminjaman

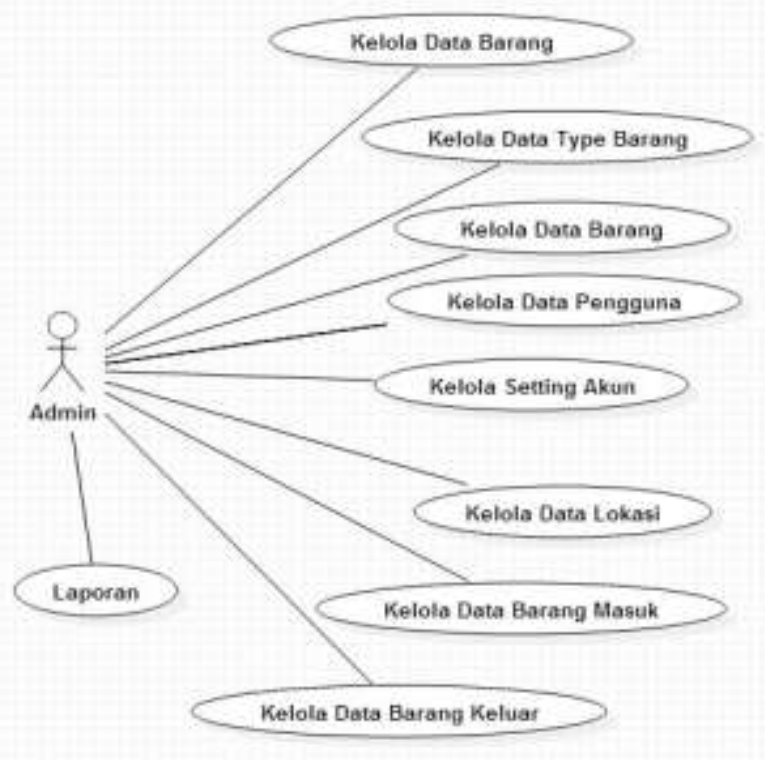

Gambar 3. Usecase Diagram
3. HASIL DAN PEMBAHASAN

3.1 Tampilan Sistem

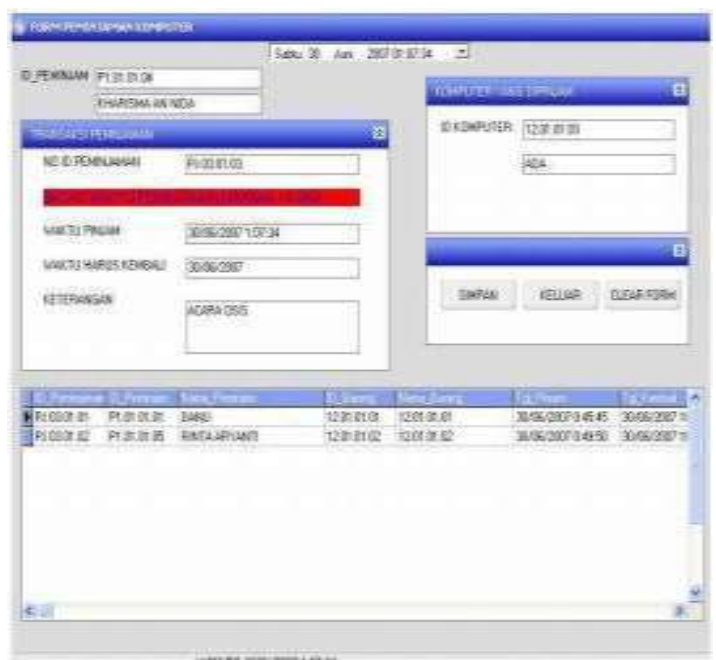

Gambar 4. Tampilan Data Peminjaman

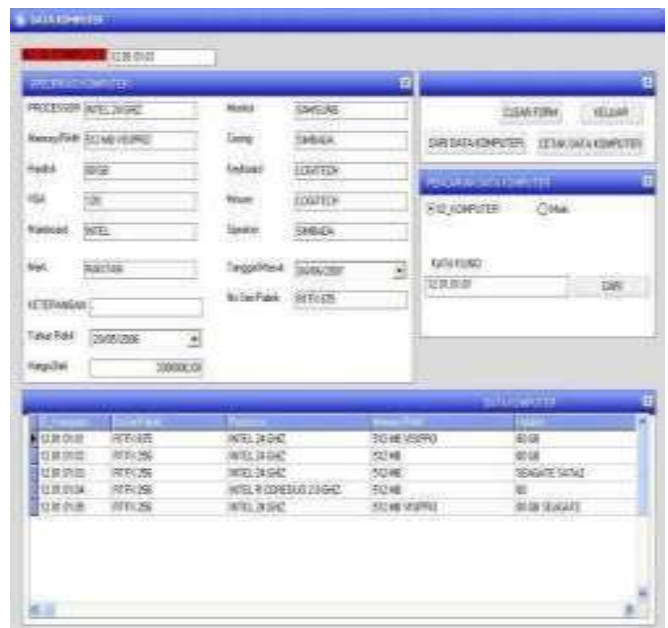

Gambar 5. Input Data Komputer

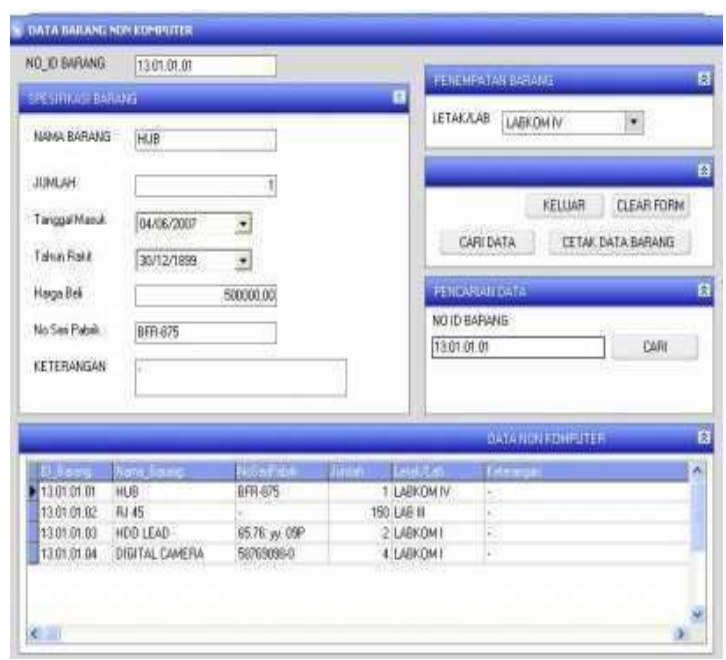

Gambar 6. Input Data Barang Non Komputer 
4. Kesimpulan

Dapat disimpulkan bahwa pembuatan aplikasi ini dapat mempermudah pengelolaan data dan meningkatkan efisiensi kerja bagian laboratorium SMK Negeri 2 Banjarmasin yaitu dengan cara mengembangkan sistem yang bersifat manual menjadi komputerisasi dengan menggunakan aplikasi delphi 7.0
5. Referensi

(1) Irmansyah, Faried, 24 April 2007, Pengantar Database.

(2) Kendal.2002. Analisis dan Perancangan Sistem.Jakarta.Prenhallindo.

(3) Kristanto, Harianto.1994, Konsep dan Perancangan Database. Yogyakarta : Andi Yogyakarta 